\title{
STUDI KELAYAKAN USAHA \\ BUDIDAYA IKAN LELE SANGKURIANG \\ DI KOTA PALANGKA RAYA \\ (Studi Kasus Usaha Budidaya Lele Sangkuriang Milik Bapak Yayan)
}

\author{
FEASIBILITY STUDY \\ OF SANGKURIANG CATFISH CULTIVATION \\ IN PALANGKA RAYA CITY \\ (Case Study of Sangkuriang Catfish Cultivation Owned by Mr. Yayan)
}

${ }^{1}$ Alexcandra Sitanggang, ${ }^{2}$ Maleha, ${ }^{3}$ Suharno

\author{
${ }^{1}$ Alumnus Program Studi Agribisnis Fakultas Pertanian Universitas Palangka Raya \\ ${ }^{2,3}$ Staf Pengajar Program Studi Agribisnis Fakultas Pertanian Universitas Palangka Raya \\ email:malehaplk@gmail.com
}

\begin{abstract}
ABSTRAK
Penelitian ini bertujuan menganalisis secara finansial usaha budidaya ikan lele sangkuriang milik Bapak Yayan. Penelitian ini merupakan penelitian kuantitatif, dilaksanakan di Jalan Rajawali VII, Kota Palangka Raya sebagai salah satu pelaku usaha yang melakukan usaha pembenihan dan pembesaran ikan lele sangkuriang menggunakan kolam tanah dan bioflok. Aspek non finansial terdiri atas aspek pasar, aspek teknis, aspek hukum, aspek sosial dan lingkungan. Banyak dan sedikit aspek yang akan dinilai serta kedalaman analisis tergantung pada besar kecilnya proyek yang akan dilakukan. Kriteria keberhasilan suatu proyek dapat dilihat dari manfaat investasi yang terdiri atas manfaat ekonomis proyek terhadap proyek itu sendiri, manfaat sosial proyek tersebut bagi masyarakat di sekitar proyek. Harga jual benih ikan lele sangkuriang yang diberikan oleh Bapak Yayan adalah sebesar Rp 350/ekor dan harga lele konsumsi sebesar Rp 25.000/Kg. Hasil perhitungan kelayakan usaha budidaya ikan lele sangkuriang layak diusahakan yang dapat dilihat dari NPV Rp 158.990.654, Gross B/C diperoleh sebesar 2,7, Net $B / C$ diperoleh sebesar 4,8 (layak), IRR sebesar 87,16\%, dan Payback Period selama 2 tahun 5 bulan (layak).
\end{abstract}

Kata kunci: Budidaya, kelayakan usaha, lele sangkuriang, Palangka Raya

\section{ABSTRACT}

The purpose of the research is financially analyzing Mr. Yayan's sangkuriang catfish farming business is worth the effort. This research is a quantitative study, was carried out in at Jalan Rajawali VII, Kota Palangka Raya as one of the business actors that conducts sangkuriang catfish hatchery and enlargement operations using ground ponds and biofloc. Non-financial aspects consist of market aspects, technical aspects, legal aspects, social and environmental aspects. Many and few aspects will be assessed and the depth of the analysis depends on the size of the project to be carried out. The criteria for success of a project can be seen from the investment benefits that consist of the economic benefits of the project against the project itself, the social benefits of the project for the community around the project. The selling price of sangkuriang catfish seed given by Mr. Yayan is Rp. 350/head and the price of consumption catfish is Rp. 25,000/kg. The results of the business feasibility of sangkuriang catfish farming 
are very feasible to be cultivated, which can be seen from the NPV IDR 158.990.654 by Gross B/C obtained by 2,7 (feasible) by Net B/C obtained by 4,8 (feasible), IRR by 87,16\%, and Payback Period for 2 years 5 months (feasible).

Keywords: Cultivation, feasibility, Palangka Raya, sangkuriang catfish

\section{PENDAHULUAN}

Pembangunan sektor kelautan dan perikanan memegang peranan yang cukup penting dalam meningkatkan perekonomian Indonesia pada umumnya dan di Kalimantan Tengah khususnya. Hal ini didukung dengan begitu besar dan berlimpahnya sumberdaya alam yang dapat dimanfaatkan untuk kemakmuran rakyat apabila dikelola dengan baik dan benar. Sektor perikanan menjadi bagian yang sangat penting dalam pembangunan nasional terutama dalam penyediaan bahan pangan hewani, penyediaan bahan baku untuk mendorong agroindustri, penyediaan lapangan kerja dan usaha serta melestarikan sumberdaya perikanan dan lingkungan hidup (Kementerian Kelautan dan Perikanan Republik Indonesia, 2017).

Badan Pusat Statistik mencatat, subsector perikanan budidaya punya peluang besar dalam memberikan kontribusi terhadap Produk Domestik Bruto (PDB) Indonesia. Sebagai gambaran tahun 2015 lalu subsector perikanan budidaya memberikan kontribusi sebesar $1,41 \%$ terhadap PDB Indonesia dengan laju pertumbuhan PDB pada tahun yang sama sebesar $15,79 \%$ di atas laju pertumbuhan PDB sektor perikanan dan PDB Indonesia (Kementerian Kelautan dan Perikanan Republik Indonesia, 2017). Produksi budidaya ikan air tawar dapat dilihat dalamTabel 1.

Tabel 1. Produksi Budidaya Ikan Air Tawar di Kota Palangka Raya Tahun 2013 - 2017

\begin{tabular}{ccc}
\hline Tahun & $\begin{array}{c}\text { Produksi } \\
\text { (Ton) }\end{array}$ & $\begin{array}{c}\text { Perkembangan } \\
(\%)\end{array}$ \\
\hline 2013 & $8.411,15$ & \\
2014 & $9.203,65$ & 8,61 \\
2015 & $9.670,60$ & 4,82 \\
2016 & $11.179,00$ & 13,49 \\
2017 & $13.000,72$ & 14,01 \\
\hline Rata-Rata & & 8,18 \\
\hline
\end{tabular}

Sumber: Dinas Perikanan Kota Palangka Raya, 2018.

Berdasarkan Tabel 1 diketahui bahwa produksi ikan air tawar di Kota Palangka Raya setiap tahunnya terus meningkat. Produksi pada tahun 2017 lebih tinggi dibandingkan dengan tahun sebelumnya. Peningkatan rata-rata produksi sebesar $8,18 \%$ setiap tahunnya. Hal ini disebabkan oleh semakin tinginya permintaan masyarakat atau konsumen terhadap ikan air tawar sehingga produksi ikan air tawar setiap tahunnya terus ditingkatkan untuk dapat memenuhi permintaan masyarakat terhadap ikan air tawar. Produksi penyebaran budidaya ikan air tawar di kolam, keramba dan KJA dilihat pada Tabel 2 . 
Tabel 2. Produksi Budidaya Ikan Air Tawar di Kolam, Keramba dan Keramba Jaring Apung (KJA) Per Kecamatan Kota Palangka Raya Tahun 2017

\begin{tabular}{lcccc}
\hline \multicolumn{1}{c}{ Kecamatan } & $\begin{array}{c}\text { Kolam } \\
\text { (Ton) }\end{array}$ & $\begin{array}{c}\text { Keramba } \\
\text { (Ton) }\end{array}$ & $\begin{array}{c}\text { KJA } \\
\text { (Ton) }\end{array}$ & $\begin{array}{c}\text { Produksi } \\
\text { (Ton) }\end{array}$ \\
\hline Pahandut & 865,75 & $6.914,15$ & 1,16 & $7.781,06$ \\
Jekan Raya & $1.953,18$ & 221,47 & 1,73 & $2.176,38$ \\
Sabangau & $2.169,14$ & 129,48 & - & $2.298,62$ \\
Bukit Batu & 634,22 & 13,28 & 0,16 & 647,66 \\
Rakumpit & 57,51 & 39,49 & - & 97,00 \\
\hline \multicolumn{1}{c}{ Jumlah } & $5.679,80$ & $7.317,87$ & 3,05 & $13.000,72$ \\
\hline
\end{tabular}

Sumber: Dinas Perikanan Kota Palangka Raya, 2018.

Berdasarkan Tabel 2, diketahui bahwa penyebaran produksi budidaya ikan air tawar untuk setiap kecamatan yang ada di Kota Palangka Raya cukup tinggi, dimana pada tahun 2017 jumlah produksi di Kecamatan Pahandut lebih tinggi dari kecamatan lainnya. Produksi yang lebih rendah berada di Kecamatan Rakumpit. Dilihat dari data tersebut dapat diketahui bahwa jumlah produksi budidaya air kolam, keramba dan KJA per kecamatan di Kota Palangka Raya cukup tinggi. Peningkatan jumlah produksi lebih dominan terhadap budidaya kolam dan keramba, maka perkembangan usaha budidaya di kolam dan keramba lebih berkembang dengan baik dibandingkan dengan KJA.
Kota Palangka Raya memiliki luas lahan yang cukup luas dan bisa dimanfaatkan dengan optimal untuk perikanan. Kota Palangka Raya merupakan salah satu sentra produksi dalam bidang perikanan yang mempunyai prospek cukup potensial untuk dikembangkan adalah budidaya ikan lele di perairan umum. Usaha budidaya ikan lele mempunyai prospek cukup potensial untuk dikembangkan di perairan umum dengan potensi lahan tersedia dan pemanfaatan sungai untuk usaha budidaya ikan dalam Karamba dan KJA serta lahan darat untuk budidaya kolam (Dinas Perikanan Kota Palangka Raya, 2017). Perkembangan produksi ikan lele dapat dilihat pada Tabel 3.

Tabel 3. Produksi Ikan Lele di Kota Palangka Raya Tahun 2013 - 2017

\begin{tabular}{ccc}
\hline Tahun & $\begin{array}{c}\text { Produksi } \\
(\text { Ton })\end{array}$ & $\begin{array}{c}\text { Perkembangan } \\
(\%)\end{array}$ \\
\hline 2013 & 134,10 & \\
2014 & 290,94 & 53,9 \\
2015 & 367,59 & 20,8 \\
2016 & $1.170,76$ & 68,6 \\
2017 & $1.332,93$ & 12,1 \\
\hline Rata-Rata & & 31,1 \\
\hline
\end{tabular}

Sumber: Dinas Perikanan Kota Palangka Raya, 2018.

Berdasarkan Tabel 3, diketahui bahwa perkembangan produksi ikan lele di Kota Palangka Raya setiap tahunnya mengalami peningkatan. Produksi budidaya ikan lele terbesar adalah tahun 2017 dengan produksi sebesar 1.332,93 ton. Produksi ikan lele di Kota Palangka
Raya mengalami perkembangan dengan rata-rata $31,1 \%$ setiap tahunnya. Adanya perkembangan produksi ikan lele yang terus meningkat dari tahun ke tahun, ini diakibatkan oleh permintaan masyarakat (konsumen) yang semakin tinggi terhadap 
ikan lele sehingga produksi ikan lele terus dikembangkan.

Rata-rata konsumsi per kapita seminggu menurut komoditi makanan dan golongan pengeluaran Kota Palangka Raya tahun 2017 sebesar 3.066.893,28 kg/tahun. Konsumsi masyarakat terhadap lele ini sejalan dengan jumlah penduduk Kota Palangka Raya yang mengkonsumsi ikan lele. Jumlah penduduk di Kota Palangka Raya sebesar 258.156 jiwa (Badan Pusat Statistik Kota Palangka Raya, 2018).

Jumlah konsumsi tersebut merupakan konsumsi yang sangat tinggi, jika dilihat dari jumlah produksi ikan lele pada tahun 2017 hanya mencapai1.332.93 ton atau $1.332 .930 \mathrm{~kg}$. Jika dibandingkan dengan konsumsi ikan lele, jumlah produksi tersebut tidak cukup untuk memenuhi kebutuhan konsumsi ikan lele, oleh karena itu jumlah produksi atau budidaya ikan lele di Kota Palangka Raya harus ditingkatkan lagi guna memenuhi kebutuhan konsumsi ikan lele di Kota Palangka Raya.

Salah satu pelaku yang mengusahakan komoditas ikan lele sangkuriang adalah Bapak Yayan yang berlokasi di Jalan Rajawali VII, Kota Palangka Raya. Dalam memulai usaha budidaya ikan lele sangkuriang ini Bapak Yayan melakukan pinjaman ke Bank BRI senilai Rp. 25.000.000 dengan tingkat suku bunga KUR sebesar 7\%. Tujuan penelitian ini adalah menganalisis secara finansial usaha budidaya ikan lele sangkuriang milik Bapak Yayan.

\section{METODE PENELITIAN}

Analisis data dilakukan secara kualitatif dan kuantitatif. Analisis secara kualitatif dilakukan secara deskriptif untuk menggambarkan kelayakan dalam usaha budidaya lele ini. Analisis yang digunakan meliputi aspek kelayakan usaha yang terdiri dari aspek pasar dan aspek teknis. Analisis secara kuantitatif digunakan untuk menilai kelayakan usaha budidaya lele secara finansial. Alat analisis yang digunakan adalah analisis kelayakan finansial berdasarkan kriteria $N P V, I R R$, Gross B/C, Net B/C dan Payback Period.

Untuk menjawab tujuan dari penelitian ini adalah dengan menggunakan analisis kelayakan usaha secara finansial maka metode analisis data yang digunakan adalah, sebagai berikut:

NPV (Net Present Value), dapat dirumuskan (Husnan \& Suwarsono, 2005):

$$
\mathbf{N P V}=\sum_{t=\underline{u}}^{\mathrm{n}} \frac{u-L}{(1+t)^{\mathrm{t}}}
$$

\section{Keterangan:}

$$
\begin{aligned}
\mathrm{Bt}= & \text { Manfaat pada tahun } \mathrm{t} \\
\mathrm{Ct}= & \text { Biaya pada tahun } \mathrm{t} \\
\mathrm{t}= & \text { Tahun kegiatan bisnis, tahun awal } \\
& \text { bias tahun } 0 \text { atau tahun } 1 \\
\mathrm{i}= & \text { Tingkat DF (Discount Factor) } \\
\mathrm{n}= & \text { Tahun terakhir dimana jumlah arus } \\
& \text { kas masih belum bias menutup } \\
& \text { investasi mula-mula. }
\end{aligned}
$$

Kriteria:

- $N P V>0$, artinya usaha tersebut sudah dinyatakan menguntungkan dan dapat dilaksanakan atau diteruskan.

- $N P V<0$, artinya usaha merugikan dan tidak dapat dilaksanakan.

- $N P V=0$, artinya usaha tersebut tidak untung dan tidak rugi.

IRR, dapat dirumuskan (Gittinger, 1986):

$$
\mathrm{IRR}=\mathrm{i}+\frac{\mathrm{NPV}}{\mathrm{NPV}-\mathrm{NPV}}(\mathrm{i}-\mathrm{i})
$$

Keterangan:

$$
\begin{aligned}
\mathrm{i}_{1}= & \begin{array}{l}
\text { Discount factor } \\
\text { menghasilkan NPV positif }
\end{array} \\
\mathrm{i}_{2}= & \begin{array}{l}
\text { Discount factor } \\
\text { menghasilkan NPV negatif }
\end{array} \\
\mathrm{NPV}_{1}= & \text { NPV positif } \\
\mathrm{NPV}_{2}= & \text { NPV negatif }
\end{aligned}
$$

Kriteria: 
- IRR < i, hal ini berarti bahwa usaha atau proyek tersebut tidak layak secara finansial.

- $\quad$ IRR = i, hal ini berarti bahwa usaha atau proyek tersebut berada dalam break even point.

- IRR > i, hal ini berarti bahwa usaha atau proyek tersebut layak secara finansial.

Gross B/C, dapat dirumuskan (Clive Gray, 2005):

$$
\operatorname{Gross} \frac{\mathrm{B}}{\mathrm{C}}=\frac{\sum_{\mathrm{t}=1}^{\mathrm{u}} \frac{\mathrm{B}-\mathrm{C}}{(1+\mathrm{l}) \mathrm{t}}}{\sum_{\mathrm{t}=1}^{\mathrm{u}} \frac{\mathrm{C}-\mathrm{B}}{(1+\mathrm{l}) \mathrm{t}}}
$$

Keterangan:

$\mathrm{Bt}=$ Manfaat (Benefit) pada tahun ke-t

$\mathrm{Ct}=$ Biaya $($ Cost $)$ pada tahun ke-t

$\mathrm{I}=$ Discount Factor

$\mathrm{t}=$ Umur proyek

$\mathrm{n}=$ Tahun terakhir dimana jumlah arus kas masih belum bias menutup investasi mula-mula.

Kriteria:

- Gross B/C > 1 (satu) berarti proyek (usaha) layak dikerjakan

- Gross B/C < 1 (satu) berarti proyek tidak layak dikerjakan

- Gross B/C = 1 (satu) berarti proyek dalam keadaan BEP.

Net Benefit Cost Ratio (Net B/C) dapat dirumuskan (Clive Gray, 2005):

$$
\operatorname{Net} \frac{B}{C}=\frac{\sum_{t=1}^{\mathrm{u}} \frac{\mathrm{B}-\mathrm{C}}{(1+\mathrm{l})^{\mathrm{I}}}}{\sum_{\mathrm{t}=1}^{\mathrm{u}} \frac{\mathrm{C}-\mathrm{B}}{(1+\mathrm{l})^{\mathrm{L}}}}
$$

Keterangan:

$\mathrm{Bt}=$ Manfaat (Benefit) pada tahun ke- $\mathrm{t}$

$\mathrm{Ct}=$ Biaya (Cost) pada tahun ke-t

$\mathrm{i}=$ Discount Faktor

$\mathrm{t}=$ Umur proyek

$\mathrm{n}=$ Tahun terakhir dimana jumlah arus kas masih belum bias menutup investasi mula-mula.

Kriteria:
- Net $B / C>1$ (satu) berarti proyek (usaha) layak dikerjakan

- Net $B / C<1$ (satu) berarti proyek tidak layak dikerjakan

- Net $B / C=1$ (satu) berarti proyek dalam keadaan BEP.

Payback Period. Rumus periode pengembalian apabila arus kas per tahun jumlahnya berbeda (Brigham \& Houston, 2011):

$$
\text { Payback Period }=\mathrm{n}+(\mathrm{a}-\mathrm{b}) /(\mathrm{c}-\mathrm{b}) \times 1
$$

tahun

Keterangan:

$\mathrm{n}=$ Tahun terakhir dimana jumlah arus kas masih belum bisa menutup investasi mula-mula.

$\mathrm{a}=$ Jumlah investasi mula-mula.

$\mathrm{b}=$ Jumlah kumulatif arus kas pada tahun ke-n

$\mathrm{c}=$ Jumlah kumulatif arus kas pada tahun ke-n +1

Kriteria:

Semakin cepat tingkat pengembalian investasinya, maka investasi tersebut semakin baik dilaksanakan.

\section{HASIL DAN PEMBAHASAN}

Kelayakan Usaha Budidaya Lele Sangkuriang Milik Bapak Yayan Aspek Non Finansial

\section{Aspek Pasar}

Menurut Umar (2007), pasar merupakan suatu kelompok orang yang diorganisasikan untuk melakukan tawar menawar, sehingga demikian terbentuk harga. Aspek pasar mengkaji harga jual dan strategi pemasaran serta pengkiraan penjualan yang dilakukan dalam usaha budidaya lele sangkuriang. Usaha budidaya lele sangkuriang ini ditinjau dari aspek pasar apakah layak dilakukan, hal ini terkait dengan peluang pasar komoditas ikan lele yang masih memiliki peluang besar. Sedangkan jumlah produksi ikan lele sangkuriang tidak memenuhi kebutuhan di 
Kota Palangka Raya, salah satunya pelaku usaha budidaya ikan lele sangkuriang yaitu Bapak Yayan hanya mampu menyumbang kebutuhan konsumsi yaitu $100 \mathrm{~kg}$ sampai dengan $250 \mathrm{~kg}$ dalam dua bulan. Hal ini menunjukkan bahwa usaha budidaya lele sangkuriang yang dilakukan oleh Bapak Yayan memiliki peluang untuk meningkatkan jumlah produksi ikan lele sangkuriang.

Produk yang ditawarkan oleh usaha budidaya ikan lele sangkuriang yang dilakukan oleh Bapak Yayan adalah benih ikan lele dan lele konsumsi. Strategi pemasaran yang dilakukan oleh Bapak Yayan adalah dengan menjual secara langsung kepada masyarakat ataupun warung makan tertentu sesuai dengan pesanan. Harga jual benih ikan lele sangkuriang yang ditawarkan oleh Bapak Yayan sebesar Rp 350/ekor dan harga lele konsumsi sebesar Rp 25.000/kg.

\section{Aspek Teknis}

Secara teknis berhubungan dengan penyedian input dan output. Input dari usaha lele sangkuriang adalah pakan, vitamin, oksigen, dan tenaga kerja sedangkan output dalam usaha budidaya lele sangkuriang ini adalah benih ikan lele dan lele konsumsi. Usaha budidaya lele sangkuriang dilakukan oleh Bapak Yayan berada di pekarangan belakang rumah dengan luas $20 \times 40 \mathrm{~m}^{2}$. Proses yang dilakukan pertama kali adalah membuat kolam untuk pembenihan dan pembesaran ikan lele sangkuriang. Dalam proses pembenihan menggunakan pakan $M e M$ dan Nori sebanyak 1 sak dalam jumlah benih 10.000 ekor sampai panen. Dalam proses pembesaran menggunakan pakan pellet sebanyak 2 sak dalam jumlah benih yang didederkan sebanyak 1.500 ekor sampai panen. Obat-obatan yang digunakan untuk mencegah penyakit adalah daun pepaya dan mengkudu. Alat bantu lain yang digunakan adalah serokan ikan, pompa air, dan peralatan pengemasan benih ikan lele sangkuriang seperti plastik dan oksigen.

\section{Aspek Hukum}

Aspek hukum adalah aspek yang membahas mengenai legalitas dari suatu usaha. Tujuan dari aspek hukum adalah untuk melihat keabsahan dan kesempurnaan serta keaslian dari dokumen-dokumen yang dimiliki. Usaha budidaya ikan lele sangkuriang milik Bapak Yayan sudah memiliki badan hukum pada tanggal 13 November 2017 dengan Nomor: AHU-0016331.AH.01.07.

\section{Aspek Sosial dan Lingkungan}

Usaha budidaya ikan lele sangkuriang milik Bapak Yayan tidak memberikan dampak buruk atau negatif terhadap masyarakat dan lingkungan sekitar. Hal ini terkait bahwa usaha budidaya milik Bapak Yayan tidak menghasilkan limbah yang merugikan bagi lingkungan. Usaha budidaya milik Bapak Yayan memiliki dampak positif bagi masyarakat sekitar, karena usaha milik Bapak Yayan salah satu penyumbang produksi ikan lele sangkuriang yang dibutuhkan oleh masyarakat yang gemar ikan lele.

\section{Analisis Arus Kas (Cash Flow Analisis) 1. Arus Penerimaan (Inflow)}

Penerimaan merupakan hasil perkalian antara kuantitas produksi yang dihasilkan dengan harga jual yang ditetapkan oleh suatu periode (Husnan \& Suwarsono, 2005). Pada usaha budidaya ikan lele sangkuriang milik bapak Yayan terdiri dari dua sumber yaitu penerimaan dari penjualan pembenihan lele dan penjualan lele konsumsi.

Kegiatan pembenihan dilakukan produksi dalam 40 hari sekali produksi atau 8 kali periode produksi dalam satu tahun. Pada pembesaran ikan lele sangkuriang dilakukan satu kali produksi dalam satu periode (dua bulan) atau dalam satu tahun 6 kali periode panen. Penerimaan yang diperoleh dari penjualan benih ikan lele berukuran $5 \mathrm{~cm}$ sampai 
dengan berukuran $7 \mathrm{~cm}$ dengan harga jual Rp. 300 - Rp. 350 per ekor dan penjualan lele konsumsi dengan harga Rp. 13.000 Rp. 25.000 per kilogram (6-8 ekor per kilogram). Produksi usaha budidaya lele sangkuriang milik Bapak Yayan dapat dilihat pada Tabel 4.

Tabel 4. Arus Penerimaan Usaha Budidaya Lele Sangkuriang Milik Bapak Yayan

\begin{tabular}{|c|c|c|c|c|c|}
\hline Tahun Penjualan & $\begin{array}{c}\text { Panen } \\
\text { Per } \\
\text { Periode }\end{array}$ & $\begin{array}{c}\text { Jumlah } \\
\text { Periode } \\
\text { Produksi } \\
\text { (Kali) }\end{array}$ & $\begin{array}{l}\text { Total } \\
\text { Produksi } \\
(\mathrm{Kg})\end{array}$ & $\begin{array}{c}\text { Harga } \\
\text { (Rp) }\end{array}$ & $\begin{array}{c}\text { Total } \\
\text { Penerimaan } \\
\text { Per Tahun } \\
\text { (Rp) }\end{array}$ \\
\hline $\begin{array}{l}\text { 1. Penjualan Benih } \\
\text { Lele (Ekor) }\end{array}$ & & & & & \\
\hline 0 & 0 & 0 & 0 & 0 & 0 \\
\hline 1 & 10.000 & 8 & 80.000 & 300 & 24.000 .000 \\
\hline 2 & 12.000 & 9 & 108.000 & 300 & 32.400 .000 \\
\hline 3 & 12.000 & 9 & 108.000 & 300 & 32.400 .000 \\
\hline 4 & 15.000 & 9 & 135.000 & 300 & 47.250 .000 \\
\hline 5 & 15.000 & 9 & 135.000 & 300 & 47.250 .000 \\
\hline \multicolumn{5}{|c|}{ Jumlah } & 183.300 .000 \\
\hline \multicolumn{6}{|l|}{$\begin{array}{l}\text { 2. Penjualan Lele } \\
\text { Konsumsi (Kg) }\end{array}$} \\
\hline 0 & 0 & 0 & 0 & 0 & 0 \\
\hline 1 & 200 & 6 & 1.200 & 13.000 & 15.600 .000 \\
\hline 2 & 220 & 6 & 1.260 & 15.000 & 19.800 .000 \\
\hline 3 & 220 & 6 & 1.260 & 19.000 & 25.080 .000 \\
\hline 4 & 250 & 6 & 1.500 & 22.000 & 33.000 .000 \\
\hline 5 & 250 & 6 & 1.500 & 25.000 & 37.500 .000 \\
\hline \multicolumn{5}{|c|}{ Jumlah } & 130.980 .00 \\
\hline \multicolumn{5}{|c|}{ Total } & 314.280 .000 \\
\hline
\end{tabular}

Sumber: Data Primer yang Diolah, 2019.

Berdasarkan Tabel 4, dapat dilihat bahwa pada tahun pertama terdapat $8 \mathrm{kali}$ periode produksi benih ikan lele dengan jumlah 10.000 ekor per periode yaitu 8 kali produksi dan pada tahun selanjutnya tedapat 9 kali produksi. Pada pembesaran ikan lele konsumsi setiap tahunnya terdapat 6 kali periode produksi. Penerimaan yang diperoleh dari penjualan benih ikan lele sangkuriang adalah Rp 183.300.000 dan penerimaan yang diperoleh dari penjualan lele konsumsi adalah Rp 130.980.000, maka total penerimaan yang diperoleh dari usaha budidaya lele sangkuriang milik Bapak Yayan selama 5 tahun adalah $\mathrm{Rp}$ 314.280.000.

Tabel 5. Penerimaan Bersih Usaha Budidaya Lele Sangkuriang Milik Bapak Yayan

\begin{tabular}{cccc}
\hline Tahun & $\begin{array}{c}\text { Total Biaya } \\
(\mathrm{Rp})\end{array}$ & $\begin{array}{c}\text { Penerimaan } \\
(\mathrm{Rp})\end{array}$ & $\begin{array}{c}\text { Penerimaan Bersih } \\
(\mathrm{Rp})\end{array}$ \\
\hline 0 & 41.655 .000 & 0 & -41.655 .000 \\
1 & 12.359 .000 & 39.600 .000 & 27.241 .000 \\
2 & 11.071 .000 & 52.200 .000 & 41.129 .000 \\
3 & 13.841 .000 & 57.480 .000 & 43.639 .000 \\
4 & 12.201 .000 & 80.250 .000 & 68.049 .000
\end{tabular}




\begin{tabular}{crrr}
5 & 12.201 .000 & 90.560 .000 & 72.549 .000 \\
\hline Total & 103.328 .000 & 314.280 .000 & 210.952 .000 \\
\hline
\end{tabular}

Sumber: Data Primer yang Diolah, 2019.

Berdasarkan Tabel 5, dapat dilihat bahwa biaya total yang dikeluarkan sebesar Rp 103.328.000 dan total penerimaan yang diperoleh selama 5 tahun sebesar $\mathrm{Rp}$ 314.280.000, maka diperoleh penerimaan bersih dari usaha budidaya lele sangkuriang milik Bapak Yayan sebesar Rp 210.952.000.

\section{Arus Pengeluaran (Outflow)}

Pada analisis kelayakan finansial pada usaha budidaya ikan lele sangkuriang milik Bapak Yayan terdiri dari biaya investasi dan biaya operasional dan pemeliharaan.

Tabel 6. Rincian Biaya Pada Usaha Budidaya Lele Sangkuriang Milik Bapak Yayan

\begin{tabular}{crrr}
\hline Tahun & $\begin{array}{c}\text { Biaya Investasi } \\
(\mathrm{Rp})\end{array}$ & $\begin{array}{c}\text { Biaya Operasional } \\
(\mathrm{Rp})\end{array}$ & $\begin{array}{c}\text { Total Biaya } \\
(\mathrm{Rp})\end{array}$ \\
\hline 0 & 41.655 .000 & 0 & 41.655 .000 \\
1 & 0 & 12.359 .000 & 12.359 .000 \\
2 & 0 & 11.071 .000 & 11.071 .000 \\
3 & 2.500 .000 & 11.341 .000 & 13.841 .000 \\
4 & 0 & 12.201 .000 & 12.201 .000 \\
5 & 0 & 12.201 .000 & 12.201 .000 \\
\hline Total & & & 103.328 .000
\end{tabular}

Sumber: Data Primer yang Diolah, 2019.

Berdasarkan Tabel 6, diketahui bahwa biaya investasi yang ditanamkan pada awal usaha budidaya lele sangkuriang milik Bapak Yayan sebesar Rp 41.6555.000 yaitu untuk pembangunan kolam dan penyediaan peralatan. Pada tahun pertama biaya operasional dan pemelihaaran yang dikeluarkan sebesar Rp 12.359.000, termasuk angsuran KUR BRI yang dibayar selama 12 bulan dengan angsuran sebesar $\mathrm{Rp} 146.000$ setiap bulannya. Pada tahun kedua biaya operasional dan pemeliharaan yang dikeluarkan sebesar Rp 11.071.000. Pada tahun ketiga biaya yang diinvestasikan sebesar Rp 2.500.000 yaitu untuk pembangunan kolam kayu dan bioflok dan biaya operasional dan pemeliharaan yang dikeluarkan sebesar Rp 11.341.000. Pada tahun keempat biaya operasional dan pemeliharaan yang dikeluarkan sebesar Rp
12.201.000. Pada tahun kelima biaya operasional dan pemeliharaan yang dikeluarkan sebesar Rp 12.201.000. Dengan demikian, total biaya yang dikeluarkan pada usaha budidaya lele sangkuriang milik Bapak Yayan sebesar $\mathrm{Rp}$ 103.328.000 yang terdiri dari biaya investasi dan biaya operasional.

\section{Analisis Kelayakan Finansial}

Tingkat discount factor atau tingkat suku bunga yang digunakan adalah $7 \%$, penentuan tingkat suku bunga ini berdasarkan tingkat suku bunga KUR (Kredit Usaha Rakyat) yang diberikan Bank BRI Cabang Kota Palangka Raya. Dalam analisis finansial, kriteria investasi yang digunakan untuk menilai kelayakan proyek yaitu $N P V$, Gross B/C, Net B/C, IRR dan Payback Periode.

Tabel 7. Perhitungan Analisis NPV, Gross B/C dan Net B/C Pada Usaha Budidaya Lele Sangkuriang Milik Bapak Yayan 


\begin{tabular}{|c|c|c|c|c|c|c|c|c|}
\hline \multirow{2}{*}{ Tahun } & \multicolumn{3}{|c|}{ Biaya (Rp) } & \multirow{2}{*}{$\begin{array}{l}\text { Penerimaan } \\
\text { (Rp) }\end{array}$} & \multirow{2}{*}{$\begin{array}{c}D f \\
7 \%\end{array}$} & \multirow{2}{*}{$\begin{array}{c}P V \text { Cost } \\
(\mathrm{Rp})\end{array}$} & \multirow{2}{*}{$\begin{array}{l}P V \text { Benefit } \\
\text { (Rp) }\end{array}$} & \multirow{2}{*}{$\begin{array}{l}N P V \\
\text { (Rp) }\end{array}$} \\
\hline & Investasi & Operasional & Total & & & & & \\
\hline 0 & 41.655 .000 & 0 & 41.655 .000 & 0 & 1,00 & 41.655 .000 & 0 & -41.655 .000 \\
\hline 1 & 0 & 000 & & 00 & 0,93 & & 46 & \\
\hline 2 & 0 & 11.071 .000 & 11.071 & 52.200 .000 & 0,87 & 9.6 & 02 & 35.923 .661 \\
\hline 3 & 2.500 .000 & 11.341 .000 & 13.84 & 57.480 .000 & 0,82 & 11.298 & 02 & 35.622 .423 \\
\hline 4 & 0 & 12. & 12. & & 0,76 & & & 56 \\
\hline 5 & 0 & 12.201 .000 & 12.201 .000 & 90.560 .000 & 0,71 & & & .434 \\
\hline & & & & & & 92.180 .915 & 251.171 .569 & 158.990 .654 \\
\hline
\end{tabular}

Sumber: Data Primer yang Diolah, 2019.

Berdasarkan Tabel 7, perhitungan cashflow diperoleh nilai $N P V$ sebesar Rp 158.990.654. Hal ini menunjukkan bahwa usaha budidaya lele sangkuriang milik Bapak Yayan dapat memberikan manfaat bersih sebesar Rp 158.990.654 selama kurun waktu 5 tahun. Dengan demikian, berdasarkan kriteria $N P V$ usaha budidaya lele sangkuriang milik Bapak Yayan layak untuk dijalankan. Pada usaha budidaya ikan lele sangkuriang milik Bapak Yayan, Gross B/C yang diperoleh adalah 2,7. Hal ini berarti setiap Rp 1.000 biaya yang dikeluarkan untuk menjalankan usaha ini akan menghasilkan manfaat bersih sebesar Rp 2.700. Berdasarkan kriteria Gross B/C usaha budidaya lele sangkuriang milik Bapak Yayan layak untuk dijalankan. Selanjutnya $\mathrm{Net} B / C$ yang diperoleh adalah 4,8 artinya setiap Rp 1.000 biaya yang dikeluarkan untuk menjalani usaha ini akan menghasilkan manfaat sebesar Rp 4.800. Berdasarkan kriteria Net $B / C$ usaha budidaya lele sangkuriang milik Bapak Yayan layak untuk dijalankan.

Tabel 8. Perhitungan Analisis IRR pada Usaha Budidaya Lele Sangkuriang Milik Bapak

\begin{tabular}{|c|c|c|c|c|c|c|c|c|c|c|}
\hline Tahun & $\begin{array}{l}\text { Total } \\
\text { Biaya } \\
\text { (Rp) }\end{array}$ & $\begin{array}{c}\text { Penerimaan } \\
\text { (Rp) }\end{array}$ & $\begin{array}{c}D f \\
87 \%\end{array}$ & $\begin{array}{c}P V \text { Cost } \\
(\mathrm{Rp})\end{array}$ & $\begin{array}{l}P V \text { Benefit } \\
\text { (RP) }\end{array}$ & $\begin{array}{l}N P V \\
\text { (Rp) }\end{array}$ & $\begin{array}{c}D f \\
88 \%\end{array}$ & $\begin{array}{c}P V \text { Cost } \\
(\mathrm{Rp})\end{array}$ & $\begin{array}{l}P V \text { Benefit } \\
\text { (RP) }\end{array}$ & $\begin{array}{l}\text { NPV } \\
\text { (Rp) }\end{array}$ \\
\hline 0 & 41.655 .000 & 0 & 1,00 & 41.655 .000 & 0 & -41.655 .000 & 1,00 & 41.655 .000 & 0 & -41.655 .000 \\
\hline 1 & 12.359 .000 & 39.600 .000 & 0,53 & 6.609 .091 & 21.176 .471 & 14.567 .380 & 0,53 & 6.573 .936 & 21.063 .830 & 14.489 .894 \\
\hline 2 & 11.071 .000 & 52.200 .000 & 0,29 & 3.165 .947 & 14.927 .507 & 11.761 .560 & 0,29 & 3.132 .356 & 14.769 .126 & 11.636 .770 \\
\hline 3 & 13.841 .000 & 57.480 .000 & 0,15 & 2.116 .619 & 8.790 .062 & 6.673 .443 & 0,15 & 2.083 .022 & 8.650 .540 & 6.567 .518 \\
\hline 4 & 12.201 .000 & 80.250 .000 & 0,08 & 997.767 & 6.562 .641 & 5.564 .874 & 0,08 & 976.706 & 6.424 .120 & 5.447 .414 \\
\hline \multirow[t]{2}{*}{5} & 12.201 .000 & 90.560 .000 & 0,04 & 533.565 & 3.706 .224 & 3.172 .659 & 0,04 & 519.525 & 3.608 .697 & 3.089 .173 \\
\hline & & & NPV1 & 55.077 .988 & 55.162 .904 & 84.916 & NPV2 & 54.940 .546 & 54.516 .313 & -424.233 \\
\hline
\end{tabular}

Sumber: Data Primer yang Diolah, 2019.

Berdasarkan tingkat suku bunga pinjaman dari Bank BRI sebesar 7\%. Nilai IRR yang diperoleh sebesar $87,16 \%$ yang menunjukkan bahwa tingkat pengembalian yang diberikan usaha atas modal yang telah diinvestasikan sebesar $\quad 87,16 \%$. Berdasarkan kriteria IRR, maka usaha budidaya lele sangkuriang milik Bapak Yayan layak untuk dijalankan.

Tabel 9. Perhitungan Payback Period pada Usaha Budidaya Lele Sangkuriang Milik Bapak Yayan

\begin{tabular}{ccrcrc}
\hline Tahun & $\begin{array}{c}\text { Total Biaya } \\
(\mathrm{Rp})\end{array}$ & $\begin{array}{c}\text { Penerimaan } \\
(\mathrm{Rp})\end{array}$ & $\begin{array}{c}\text { Penerimaan } \\
\text { Bersih } \\
(\mathrm{Rp})\end{array}$ & $\begin{array}{c}\text { Arus Kas } \\
(\mathrm{Rp})\end{array}$ & $\begin{array}{c}\text { Periode } \\
(\text { Tahun })\end{array}$ \\
\hline 0 & 41.655 .000 & 0 & 41.655 .000 & & \\
1 & 12.359 .000 & 39.600 .000 & 27.241 .000 & & \\
2 & 11.071 .000 & 52.200 .000 & 41.129 .000 & 26.715 .000 & 2,5
\end{tabular}




$\begin{array}{llll}3 & 13.841 .000 & 57.480 .000 & 43.639 .000 \\ 4 & 12.201 .000 & 80.250 .000 & 68.049 .000 \\ 5 & 12.201 .000 & 90.560 .000 & 72.549 .000\end{array}$

Sumber: Data Primer yang Diolah, 2019.

Payback Periode usaha budidaya lele sangkuriang ini selama 2,5 tahun (2 tahun 5 bulan), dimana arus kas diterima pada tahun kedua yaitu sebesar $\mathrm{Rp}$ 26.715.000. Hal ini berarti berdasarkan kriteria Payback Periode bahwa usaha budidaya lele sangkuriang milik Bapak Yayan layak untuk dijalankan.

\section{KESIMPULAN}

Berdasarkan hasil penelitian dapat disimpulkan bahwa analisis kelayakan usaha budidaya ikan lele sangkuriang milik Bapak Yayan dengan tahun produksi selama 5 tahun adalah arus kas menunjukkan total penerimaan sebesar $\mathrm{Rp}$ 314.280.000, total biaya yang dikeluarkan sebesar Rp 103.328.000 dan pendapatan bersih sebesar Rp 210.952.000. Analisis finansial berdasarkan nilai kriteria investasi pada discount factor sebesar $7 \%$ didapatkan hasil perhitungan sebagai berikut: nilai $N P V>0$ sebesar $\mathrm{Rp}$ 158.990.654, nilai Gross B/C > 1 yaitu 2,7, nilai $N e t B / C>1$ yaitu 4,8 , nilai $I R R>1$ yaitu $87,16 \%$ dan payback periode selama 2 tahun 5 bulan.

\section{DAFTAR PUSTAKA}

Amri, K. dan Khariruman. (2008). Buku Pintar Budidaya Ikan Konsumsi. Jakarta: Agri Media Pustaka.

Andika, Y. S. (2012). Analisis Kelayakan Usaha Pembenihan dan Pembesaran Ikan Lele Sangkuriang (Studi Kasus: Perusahaan Parakbada, Kelurahan Katulampa, Kota Bogor, Provinsi Jawa Barat). Fakultas Ekonomi dan Manajemen. IPB. Bogor.

Ariwibowo. (2013). Kelayakan Finansial Perencanaan Pengembangan Bisnis
Pada Pembesaran Ikan Lele Sangkuriang. Institut Pertanian Bogor. Bogor.

Basahudin, M. S. dan Arie, U. (2014). Pembesaran Lele Secara Cepat. Jakarta: Penebar Swadaya.

Brigham, E. F. dan Houston, J. (2011). Dasar-Dasar Manajemen

Keuangan. Terjemahan. Edisi 10. Jakarta: Salemba Empat.

Cahyono, B. (2001). Budidaya Ikan di Perairan Umum. Yogyakarta: Kanisius.

Darseno. (2010). Buku Pintar Budidaya dan Bisnis Lele. Jakarta: Agromedia Pustaka.

Dinas Kelautan dan Perikanan Provinsi Kalimantan Tengah. (2018). Laporan Tahunan Statistik Perikanan Budidaya Kalimantan Tengah Tahun 2018. Palangka Raya: Dinas Kelautan dan Perikanan Provinsi Kalimantan Tengah.

Dinas Pertanian, Perikanan dan Peternakan Kota Palangka Raya. (2017). Potensi Perikanan di Kota Palangka Raya. Palangka Raya: Dinas Pertanian, Perikanan dan Peternakan Kota Palangka Raya.

(2018). Laporan Tahunan Statistik Perikanan Budidaya Kota Palangka Raya. Palangka Raya: Dinas Pertanian, Perikanan dan Peternakan Kota Palangka Raya.

Gray, C., Simanjuntak, P., Sabur, L. K., Maspaitella, P. F. L., dan Varley, R. C. G. (2005). Pengantar Evaluasi Proyek. Jakarta: PT. Gramedia Pustaka Utama. 
Najiyati, S. (2007). Memelihara Lele Dumbo di Kolam Taman. Jakarta: Penebar Swadaya.

Pudjobasuki, E. (2005). Aplikasi Teknologi Budidaya Ikan Lele Secara Intensif. Sidoarjo: Biotech Agro Indonesia.

Rita, N., Sarianti, T., dan Karyadi, A. (2009). Studi Kelayakan Bisnis. Departemen Agribisnis, Fakultas Ekonomi dan Manajemen. Institut Pertanian Bogor. Bogor.

Soekartawi. (1996). Ilmu Usahatani dan Penelitian Untuk Pengembangan Pertanian Kecil. Jakarta: Rajawali Press.

Umar, H. (2007). Studi Kelayakan Bisnis. Edisi Ketiga. Jakarta: PT. Gramedia Pustaka Utama. 